\title{
The Role of Reflection in the Effects of Community Service on Adolescent Development: A Meta-Analysis
}

\author{
Anne van Goethem, Anne van Hoof, Bram \\ Orobio de Castro, and Marcel Van Aken \\ Utrecht University
}

\author{
Daniel Hart \\ Rutgers University
}

\begin{abstract}
This meta-analysis assessed the effect of community service on adolescent development and the moderation of this effect by reflection, community service, and adolescent characteristics to explicate the mechanisms underlying community service effects. Random effects analyses, based on 49 studies (24,477 participants, 12 20 years old), revealed that community service had positive effects on academic, personal, social, and civic outcomes. Moderation analyses indicated that reflection was essential; the effect for studies that include reflection was substantial (mean ES $=.41$ ) while community service in the absence of reflection yielded negligible benefits (mean ES = .05). Effects increased when studies include more frequent reflection and community service, reflection on academic content, and older adolescents. These findings have implications for understanding and improving community service.
\end{abstract}

Adolescence is considered a sensitive period for the development of civic engagement and the derivation of benefits from it. This is because during adolescence the understanding of society expands (cf. Eisenberg, Cumberland, Guthrie, Murphy, \& Shepard, 2005) as do opportunities for meaningful civic participation (e.g., Youniss, McLellan, \& Yates, 1997). For these and many other reasons, community service is a commonly prescribed civic practice for adolescents. Community service, often also referred to as volunteering and service-learning, can generally be defined as "(often) organized, unpaid activities that are intended to benefit the environment, individuals, groups of people or society" (cf. National Centre for Social Research and the Institute for Volunteering Research, 2007; van Goethem et al., 2012). Community service is required for adolescents in some countries (e.g., the Netherlands; Rijksoverheid, 2007) and states (e.g., Maryland; Maryland State Department of Education, n.d.), and is promoted by innumerable national and nongovernmental agencies.

Available evidence, including four meta-analyses (Celio, Durlak, \& Dymnicki, 2011; Conway, Amel, \& Gerwien, 2009; Novak, Markey, \& Allen, 2007; White, 2001), is generally supportive of the presumption that community service is beneficial for

Correspondence concerning this article should be addressed to Anne van Goethem, Developmental Psychology, Utrecht University, Heidelberglaan 1, 3508 TC, Utrecht, Netherlands. Electronic mail may be sent to a.a.j.vangoethem@uva.nl. adolescents. Community service, volunteering, and service-learning are associated with changes conventionally regarded as beneficial for adolescents' competences and attitudes in the academic, personal, social, and civic domains (e.g., Conway et al., 2009; cf. Eyler, Giles, Stenson, \& Gray, 2001; Stukas, Clary, \& Snyder, 1999).

However, the current evidence for beneficial community service effects is based largely on studies that do not permit causal inferences, because many of the relevant studies do not include control groups and lack pre- and posttest designs. The first aim of this article is therefore to synthesize the research evidence using meta-analysis drawing only from studies featuring designs that permit inferences of causal influence. As there are relatively large conceptual and empirical overlaps among community service, volunteering, and servicelearning (Hart, Matsuba, \& Atkins, 2008), we examined studies of all three types.

\section{How and When Does Community Service Work?}

There is a variety of theoretical speculations about why, through which processes, and in which conditions community service have beneficial effects (see for an overview, e.g., Hart et al., 2008). Generally it

(C) 2014 The Authors

Child Development (c) 2014 Society for Research in Child Development, Inc. All rights reserved. 0009-3920/2014/8506-0003

DOI: $10.1111 /$ cdev.12274 
is thought that community service places adolescents in novel situations and societal contexts in which they can learn, apply, and practice various behaviors and skills as well as confront societal issues and different perspectives, values, and behaviors. These experiences theoretically teach adolescents about themselves (e.g., self-efficacy, identity), others (e.g., communication skills, attitudes toward other groups in society), responsibility to society (e.g., civic responsibility, volunteering), and stimulate related attitudes and behaviors (Hart et al., 2008). Furthermore, when incorporated in the school curriculum, the community service experiences are thought to provide more authentic and autonomous learning environments that can stimulate adolescents' academic motivation, enjoyment of learning, and academic performance (e.g., Scales, Blyth, Berkas, \& Kielsmeier, 2000).

In addition, earlier community service research suggested that community service effects may depend on the characteristics of both the community service and the adolescents who perform the community service (e.g., Furco, 2002). One particularly crucial, unresolved debate concerns the importance of what is typically labeled reflection. Reflection refers to thoughtful consideration of the community service activity and may play a critical role in the translation of the community service experience into enduring psychological benefits (e.g., Ogden \& Claus, 2006). Through critical reflection, adolescents examine the community service experience in light of particular learning objectives (e.g., Hatcher \& Bringle, 1997) that often involve consideration of the academic, personal, social, or civic meaning and (larger) context of these service experiences (cf. Toole \& Toole, 1995, p. 100). As a consequence, reflection may play a decisive role in enabling adolescents to learn and benefit from these service experiences (e.g., Billig, 2009; Hatcher, Bringle, \& Muthiah, 2004).

The conditions and processes through which community service changes teenagers is important for theoretical and programmatic reasons as it informs the understanding of adolescent psychology. For example, if community service works by providing adolescents opportunities to enact new patterns of behavior - a collection of actions that might be called the volunteer role - then it can be inferred that adolescents benefit developmentally from enacting types of altruism. Community service programs would then be designed with considerable attention to the kind and nature of the community service. Alternatively, community service's benefits might result primarily from reflection: deliberative consideration of voluntary actions on behalf of others, which might reveal moral principles, civic obligations, and social inequalities, and the connections between ideas learned in the classroom and the details of life. This would mean that the altruistic behavior serves as a raw material transformed through reflection into psychological development. The programmatic emphasis deriving from such an insight would be on the characteristics of reflection that best facilitate the transformation of generic experiences helping others into durable benefits.

In addition to assessing the efficacy of community service programs, our second aim is therefore to identify the conditions and processes through which community service influences adolescent developmental benefits. Specifically, we test the moderation of the association of community service with adolescent outcomes by reflection, characteristics of the service activity, and characteristics of the adolescents who perform this service activity.

\section{Reflection}

Despite the many claims for the centrality of reflection for effective community service, surprisingly little evidence can be marshalled in its support. One reason for the gap between these theoretical claims and empirical support is that research articles assessing community service featuring reflection have either provided little detail about the nature of the reflective experience, so it is difficult to ascertain its importance and determine what kinds of reflection are important, or characterize the reflection elements in ways that do not easily permit aggregation across studies. The consequence is that recent meta-analyses (Celio et al., 2011; Conway et al., 2009) characterize such a broad range of activities under the heading of "reflection" - for example, artwork and discussions of societal implications of service experiences - that it is difficult to infer what processes may be operative. In our view, these activities are so disparate that aggregating them into a single analytic category may obscure rather than illuminate. To avoid this problem, we contacted authors of research articles in order to obtain details about the nature of the reflection used in their studies, and consequently are able to construct meaningful analytic criteria (these are described next) for analysis. In addition, by augmenting published findings with newly collected information about the nature of the reflection experience, we are able to test hypotheses about developmental processes 
that cannot be examined using the published literature alone.

In addition, some skeptics (e.g., Hart et al., 2008) have argued that the claim for the importance of reflection for community service is weakened by the apparent similarities in outcomes between service-learning (as noted earlier, typically requiring reflection) and volunteering (most often lacking programmatic reflection). Both service-learning and volunteering are empirically associated with prosocial dispositions and civic engagement (e.g., Hart et al., 2008). One interpretation of this finding is that the feature differentiating service-learning and volunteering - structured reflection-is unnecessary.

Finally, it might be argued that the benefits of community service, especially its sociomoral benefits, are unlikely to result from reflection because moral conduct such as community service, is largely governed by intuitions and emotions largely impenetrable to reflection. Haidt (2001) seems to make such a claim when he argues that moral reasoning "does not cause moral judgment; rather, moral reasoning is usually a post hoc construction, generated after a judgment has been reached" (p. 814). As Pizarro and Bloom (2003) note, Haidt's position suggests that deliberative reasoning can do little to affect people's moral judgments and actions. In the context of community service, the implication apparently would be that reflection on community service activities is unlikely to affect these activities or the moral appraisals of them. As a consequence, reflection on community service would have little effect on sociomoral development.

Thus, the actual importance of reflection for community service effects is currently unclear. Moreover, if reflection is important, what kinds of reflection activities are responsible for these effects and represent reflection of high quality (e.g., Leming, 2001)? To clarify these issues we studied how the impact of community service is affected by the quantity and quality of reflection (e.g., Hatcher \& Bringle, 1997), represented by different reflection characteristics. Specifically, we test the moderating effects of the following qualities on the effects of reflection on developmental outcomes: The quantity of reflection, the form of reflection, the social context of reflection (cf. Eyler, 2001), the content of reflection, and the overall quality of reflection. Each of these potential moderators is discussed next.

\section{Quantity of Reflection}

Some studies suggest that the amount of reflection is positively associated with the magnitude of benefits, as it is through reflection that adolescents benefit from community service through interpretation of their experiences (for an overview, see Billig, 2009; Eyler, 2002). More frequent reflection may help to process community service experiences thoroughly (e.g., Eyler, 2002). In the literature, two aspects of the quantity of reflection can be distinguished: (a) the frequency of reflection, which refers to the number of instances of reflection, and (b) the regularity of reflection, which is often interpreted as the time spent on reflection in all community service phases: prior to community service (preparation), during community service, and when community service activities are finished (celebration, evaluation; Billig \& Weah, 2008). Theorists and practitioners have suggested that reflection benefits each of the community service phases. Reflection before adolescents start community service is claimed to be crucial as it may prepare adolescents to benefit and learn from new experiences and complex issues (cf. Eyler, 2002). Second, reflection during community service may help adolescents link thinking and action (Eyler, 2002). Finally, when community service is finished, reflection is important as it can be used to consolidate learning; adolescents examine and integrate what they have learned (Eyler, 2002; Ogden \& Claus, 2006) and consider the application of their new knowledge for other life domains and future civic activities (Eyler, 2002). The moderation effect of reflection in a particular community service phase as well as the moderation effects of both aspects of the quantity of reflection are therefore examined in this study.

\section{Form of Reflection}

Some suggest that the form of reflection can influence community service effects. For example, writing on community service experiences is an often-recommended reflection practice (e.g., Bringle \& Hatcher, 1999; Steinke, Fitch, Johnson, \& Waldstein, 2002), as specially structured assignments may focus adolescents on particular ideas or themes connected to the community service experience (Waterman, 1997). Furthermore, participating in guided discussion is often suggested to be a very effective form of reflection (e.g., Ostheim, 1995; Steinke et al., 2002). Finally, some also suggest that effective reflection would include a combination of reflection forms: verbal, written, and artistic and nonverbal forms of reflection (Billig \& Weah, 2008). The current study therefore examines the moderation effects of various individual reflection forms as well as the combination of reflection forms. 


\section{Social Context of Reflection}

Reflection effects could also be influenced by the social context in which it occurs: whether adolescents reflect on their own, with others, or both. There are suggestions that discussing community service experiences with peers and/or with teachers may strengthen community service effects (e.g., Batchelder \& Root, 1994; Steinke et al., 2002) because adolescents are presented with alternative viewpoints that may stimulate them to reflect more intensively and critically (cf. Eyler, 2002; Waterman, 1997). Furthermore, Youniss and Yates (1997) suggest that a combination of private (reflecting by oneself) and public reflection (i.e., with peers or adults) positively affects the impact of adolescents' community service on identity formation. Therefore, the current study examines the moderation effects of private reflection, reflection with others (teachers and peers), and the combination of private and public reflection.

\section{Content of Reflection}

The content of reflection, that is, the kind of community service experiences or issues on which adolescents reflect, may also play an important role in the overall impact of community service (cf. Billig \& Weah, 2008) and the facets of development affected by community service (cf. Waterman, 1997). We distinguish between four main content categories: academic, personal, social, and civic reflection (cf. overview by Molee, Henry, Sessa, \& McKinney-Prupis, 2010). Reflection on each content category is subdivided into competence-focused or attitude-focused reflection. Competence-focused reflection focuses on one's competencies and behaviors in relation to school, oneself, others, and society; attitude-focused reflection is concerned with values and motivations (reflection on one's feelings and thoughts about school, themselves, others, and society). Furthermore, as community service often includes reflection on topics that are connected to academic courses (e.g., math, science), we also examined this type of reflection to which we refer to as "reflection on academic content and competence."

Some researchers (Billig \& Weah, 2008) have claimed that reflection on attitude-related topics in the personal, social, and civic domains (e.g., perceptions about others and civic responsibility) yields the largest gains. Others have argued that developmental benefits are most evident when the desired outcomes are directly related to the reflec- tion content (e.g., Leming, 2001; cf. Waterman, 1997). For example, Leming (2001) found that reflection on moral dilemmas increased adolescents' moral awareness and responsibility (reflection and outcome both in the social domain) but not their self-esteem (personal domain) or anticipated future community service (civic domain; Leming, 2001). In the current study, we examine the moderation effect of each reflection content category on community service effects. Furthermore, we test the two ideas on the effectiveness of certain combinations of reflection contents: whether effects are stronger when adolescents reflect on attitude-related topics in the personal, social, and civic domains and whether effects are stronger when the content of the reflection and outcome category match.

\section{Overall Quality of Reflection}

In addition to the impact of separate quality aspects of reflection, we also consider how a combination of these aspects, representing overall reflection quality, may influence the impact of community service. Billig and Weah (2008) proposed a framework for overall reflection quality, with high-quality reflection characterized by (a) sufficient duration: occurring both before, during, and after community service (quantity of reflection); (b) practiced in a variety of forms: verbal, written, artistic, and nonverbal (form of reflection); and (c) focus on attitude-related topics in the personal, social, and civic domain (this criterion is further explained in the former section on the content of reflection). In this study, we examined whether the combination of these three elements moderated the overall community service effect.

\section{Characteristics of the Community Service Activity}

Community service subsumes a variety of specific activities that may have different effects on adolescents (e.g., McLellan \& Youniss, 2003). We therefore examine how community service characteristics are related to service effects. We consider the quantity of community service, the kind of community service (whether the service is for people in need or not), and whether the community service is institutionally required (e.g., required as a condition of belonging to a school or youth group), as these community service characteristics are considered important in the literature and are reported by most community service studies. 


\section{Quantity of Community Service}

A general assumption is that multiple community service experiences have larger effects on adolescents than a single community service experience (cf. Conway et al., 2009). How often adolescents have these experiences, also referred to as the quantity of community service, is therefore considered a key feature in determining community service benefits (Stukas et al., 1999). The quantity of community service can be divided into the frequency (community service hours), duration (community service weeks), and intensity (number of concentrated blocks of time in which one performs community service; cf. Billig \& Northup, 2008) of community service activities. While there is some evidence for a positive association of the quantity of community service and magnitude of outcomes (e.g., overview by Billig, 2009; Hecht, 2003; Melchior \& Bailis, 2002), the relation is not found in all studies (e.g., Conway et al., 2009). A possibility explored by some researchers is that a curvilinear relation between the quantity of community service and magnitude of service outcomes may exist, with the benefits of additional community service most evident at low levels and perhaps absent altogether at high levels. Conway et al. (2009) identified a quadratic relation between hours of community service and benefits, with positive outcomes correlated with number of community service hours up through $40 \mathrm{hr}$ of community service experience. Beyond $40 \mathrm{hr}$ of community service seemed to yield no discernible benefits for participants. However, as Conway et al. and others (e.g., overview by Scales et al., 2000) have noted, the evidence for a curvilinear relation, and if one exists, the shape of the relation, is quite sparse. In the current study, we therefore not only examine the relation between the quantity of community service and the impact of community service but also the shape of this relation.

\section{Required Community Service}

There has been a lot of debate on whether required community service, for example, as a condition of high school graduation or as part of a class, is less effective than voluntary community service (for a discussion, see Hart, Donnelly, Youniss, \& Atkins, 2007). Some have argued that requiring adolescents to perform community service reduces their intrinsic engagement and infringes on their autonomy. Others, however, point out that adolescents are accustomed to requirements and regulations, especially in their school environment, and consequently are able to benefit from many required activities (e.g., adolescents learn algebra even though they are required to attend math classes). What is traditionally considered voluntary community service is in any event often subject to social expectations, as volunteers are typically solicited by friends and family (see Hart et al., 2008). The limited empirical evidence on the issue suggests that required and voluntary community service (or volunteering) have equally beneficial effects (see Hart et al., 2008).

\section{Kind of Community Service}

A growing literature suggests that the kind of community service experience determines adolescent developmental benefits. For example, some researchers (e.g., Catalano, Haggerty, Oesterle, Fleming, \& Hawkinds, 2004; McLellan \& Youniss, 2003; Reinders \& Youniss, 2006; Steinke et al., 2002) report that community service effects are stronger when community service activities include one or more of the following three characteristics: (a) directed to people who are fragile (e.g., children, homeless people, seniors; fragile service), (b) important for others' emotional or physical well-being (e.g., providing food, housing, and support; important service), and (c) direct, personal contact with the beneficiaries of community service (personal contact). In the current study, we therefore also examine whether these kinds of community service strengthen the overall community service effect.

\section{Characteristics of the Adolescents}

Adolescents' characteristics may moderate the impact of community service and community service effects. Researchers have proposed that membership in religious communities, personality (e.g., Atkins, Hart, \& Donnelly, 2005), socioeconomic status (see Bekkers, 2007), age, sex, and ethnic background (e.g., Hamilton \& Fenzel, 1988; Hart, Atkins, Markey, \& Youniss, 2004; Hecht, 2003) may affect the benefits that adolescents derive from volunteering and community service. We found enough studies that reported age, sex, and ethnic background to assess moderating effects through meta-analysis, and discuss hypotheses related to each in the following paragraphs.

Age

Age has been proposed as a moderator of the effects of community service (e.g., Hamilton \& 
Fenzel, 1988). Older adolescents consider and value the perspectives and needs of others more than do younger adolescents (cf. Eisenberg et al., 2005; Youniss et al., 1997), and this might make older adolescents more open than younger adolescents to civic activities. A few studies have found consonant evidence for the hypothesis that the effects of community service may be more powerful among older adolescents than in younger ones (e.g., Hecht, 2003; Melchior \& Bailis, 2002). We test this possibility in the meta-analysis.

\section{Sex}

Some researchers have suggested that sex may moderate the effect of community service, with the impact greater for girls than boys (e.g., Hamilton \& Fenzel, 1988). The argument for this effect rests on findings indicating that girls are generally socialized to be more caring and nurturing than boys, which is connected to the forms of community service often performed in community service and service-learning programs (cf. Metzger \& Smetana, 2009; e.g., Scales et al., 2000). On the other hand, others have used the same reasoning to argue that boys stand to benefit most from community service. Adolescent boys may show more growth due to these kinds of community service, as they are less likely to have internalized societal norms related to community service yet, especially nurturing and caring forms of community service (e.g., Switzer, Simmons, Dew, Regalski, \& Wang, 1995).

\section{Ethnic Background}

It is commonly thought that an important determinant of adolescents' volunteering is whether they receive the opportunities to do so, for example, through organizational membership and by having proper social resources and networks (see Wilson, 2000). Generally, adolescents from ethnic minority populations have fewer opportunities to volunteer than adolescents from ethnic majority populations, and are therefore less likely to volunteer (Sundeen, Garcia, \& Raskoff, 2009). This difference could possibly also influence community service effects. For example, on the one hand, adolescents from majority populations could profit more from community service programs as they are already more attuned to this kind of behavior. On the other hand, it could be that adolescents from minority populations could profit more from community service experiences as they have more to learn or gain from the service experience (Sundeen et al., 2009). We examine the moderating effects of ethnic/racial background in the analyses that follow.

\section{Interaction of Moderator Variables}

Understanding the contributions of reflection as a component of community service is a central goal for this meta-analysis and we consider the possibility that the relation of reflection with developmental outcomes may be moderated by several of the other variables just reviewed (cf. Warter \& Grossman, 2002). For example, reflection may have a stronger impact on community service effects for older than for younger adolescent, as older adolescents may have further developed reflection capabilities (e.g., moral reasoning skills; Eisenberg et al., 2005). Similarly, interactions may exist between reflection and the other community service moderator variables. For example, the quantity of community service and reflection may strengthen each other's impact on community service effects (e.g., Blyth, Saito, \& Berkas, 1997). To test these possibilities, we assessed the interactions of reflection with all other moderators we examined.

In sum, our meta-analysis examines the impact of community service and community service programs on adolescents in general and in the domains of academic, personal, social, and civic outcomes. Furthermore, we examine how reflection and, more specifically, various aspects of reflection (the quantity of reflection, the form of reflection, the context of reflection, the content of reflection, and the quality of reflection), affect the overall community service effect. In addition, we examine how other characteristics of community service (the kind of community service and the quantity of community service) and characteristics of the adolescents who perform the community service (sex, age, and ethnic background) moderate the overall community service effect.

\section{Method}

\section{Study Selection}

We included all empirical studies that examined the effects of volunteering, community service, and service-learning on adolescent developmental benefits published between 1980 and September 2012. Four methods were used to locate relevant studies. First, using the search words "volunteer*," "community service," "service-learning," "civic engag*," and "civic involve*," in combination with the search words "adolesc*," "high school," "middle school," "secondary school," "youth," "teenage*," 
and "student," a literature search was performed in the databases PsycINFO and ERIC. Second, reference lists from meta-analyses and reviews in the field were inspected. Third, various national and international research websites (e.g., www.civicyouth.com; www.servicelearning.org) were inspected for relevant research articles. Fourth, experts in the field of volunteering, community service, servicelearning, and civic engagement were contacted in order to find additional relevant studies and include a sample of unpublished studies. Using these methods, 169 studies were initially considered for inclusion in the meta-analysis.

\section{Inclusion Criteria}

The four existing meta-analyses on community service effects (Celio et al., 2011; Conway et al., 2009; Novak et al., 2007; White, 2001) feature liberal inclusion criteria for evaluations of community service. The benefit of this approach is that estimates of the efficacy of community service are based on many effect sizes culled from a large number of studies. The cost, however, is that these meta-analyses included many studies with designs that do not provide much basis for causal inference. It is possible in meta-analysis to test for the effects of the quality of research design on the estimated effect sizes resulting from the inclusion of heterogeneous studies, and indeed we use this approach in our analyses. Yet statistical adjustment for wide variations in quality of research design may not result in the correct estimates of the efficacy of community service; the inclusion of methodologically weak studies in meta-analyses can obscure real effects that are apparent in studies featuring high-quality designs (cf. Juni, Witschi, Bloch, \& Egger, 1999).

Two of the existing meta-analyses included studies without a control group (Conway et al., 2009; White, 2001) which prevents making inferences on whether effects are due to participation in community service or are due to changes that would occur without community service participation. Furthermore, three of these meta-analyses have included studies that do not measure change through preand postcommunity service assessments (Celio et al., 2011; Novak et al., 2007; White, 2001), which prevents determining whether participants who performed community service may already differed from the control group before they started the community service, for example, due to selection bias (Higgins \& Green, 2006). We therefore applied stricter inclusion criteria (studies that did not meet these criteria were excluded from our analyses). Studies that met six criteria were included in our metaanalysis: (a) appeared between January 1980 and September 2012; (b) evaluated volunteering, community service, or service-learning; (c) included adolescents between 12 and 20 years old who did not have a mental disability; (d) featured a control group; (e) used a pre- and postmeasure or a postmeasure combined with randomization of the volunteering, community service, or service-learning (treatment); and (f) contained sufficient information to calculate or estimate effect sizes. As the number of studies with genuine random assignment to condition is extremely small in this area, random assignment could not be used as an inclusion criterion. Forty-nine studies met the inclusion criteria and are presented in Appendix S2 in the online Supporting Information. This is $29 \%$ of the total number of studies $(k=169)$ that were initially considered for this meta-analysis.

\section{Coding Procedure}

The coding scheme for the study variables, the moderation variables, and the outcome variables is presented in the online Appendix S1. The variables are based on different items, though the same labels were used to distinguish the outcome variables (e.g., the effect of community service on the outcome labeled "civic attitudes") and the reflectioncontent categories (e.g., reflection on one's civic attitudes during community service is labeled "content of reflection: civic attitudes"). Studies were coded by a trained independent research associate; $20 \%$ of the studies were also coded by the first author. Appendix S1 presents the interrater reliability for all variables (Cohen's kappas ranged from 0.62 to 1 ).

As discussed previously, published studies typically included little information on reflection characteristics. To address this shortcoming, we sent questionnaires (available upon request) to the authors of the included articles soliciting additional information about the nature of reflection in the community service they studied (questionnaires were returned for $69 \%$ of the studies). Of our final sample of 49 studies, 34 studies featured community service with reflection, there were 8 studies of community service without reflection, and for 7 studies no information was available on whether participants reflected or not. These 7 studies were not included in the reflection-moderation analyses but were used in the analysis for moderation effects by other community service characteristics and adolescent characteristics.

In addition, the three elements of the quantity of community service (community service hours, weeks, 
and number of concentrated blocks of time in which community service is performed) were highly correlated $(r \mathrm{~s}=.83-.93, p<.01)$. As the number of community service hours (community service frequency) is the most commonly reported aspect of the quantity of community service, we chose to use this measure as a proxy for the overall quantity of community service in our moderation analyses. Two extreme outliers were found for the number of community service hours (288 and $684 \mathrm{hr}$, respectively), which were replaced by the third highest number of hours (180 hr).

Furthermore, as two aspects of the kind of community service (community service [a] directed to people who are fragile and [b] is important for others' emotional or physical well-being) largely overlapped, $\chi^{2}(1,12)=21.39, p<.01$, these aspects were aggregated into one overall score representing vulnerable service groups in need of that service: community service that is important for the emotional and/or physical well-being of a vulnerable service group. Furthermore, as there was no variance in the third aspect of the kind of community service, having personal contact with the service group (all studies that provided information on this moderator, $k=20$, involved personal contact with the service group), we could not examine its impact on the overall community service effect. It, however, also means that when community service was performed for a vulnerable group in need, it also involved personal contact with this group.

\section{Index of Effect Size and Statistical Procedures}

Effect sizes were calculated as gain scores, derived from differences in (pre-post) standardized change scores between treatment and control groups. Effect sizes were weighted by the inverse variance weight, derived from each study sample size (Hedges \& Olkin, 1985). In all cases, positive effect size values indicate the service group gain was superior to the control group gain. When calculating effect sizes for outcomes in which "no effect" or "no significant effect" was reported, we assigned a conservative effect size estimate of zero. A general treatment effect as well as treatment effects for specific outcome categories were calculated (representing academic, personal, social, and civic outcome domains). If studies collected data on multiple measures within the same category, the effect sizes for these outcomes were averaged to create a single effect for that category. Main effects as well as moderation effects were calculated using a random-effects model (with RMLE) as the effect size distribution was significantly heterogeneous, $Q(48)=3744.16, p<.01 \quad$ (Raudenbush, 2009). The robustness of effects was tested by calculating failsafe numbers.

At least four studies were required in each cell for tests of moderator effects. We also assessed the distribution of relevant variables (study participants' age, sex, number of community service hours, and frequency of reflection) over the different moderator categories to check for whether moderation effects could be caused by outliers on these variables. In addition, we examined whether the kind of community service activities differed between required and unrequired community service, as this was suggested to be important in the literature. For the moderation effects of reflection characteristics, we examined for each aspect of the examined reflection categories (the quantity of reflection, the form of reflection, the social context of reflection, and the content of reflection) whether using that aspect of reflection yielded a stronger community service effect than (a) using no reflection and (b) not using that aspect of reflection but using other aspects of the same reflection category. Finally, we performed regression analyses to examine the interactions between the hypothesized moderators.

\section{Results \\ Main Effects of Community Service}

The frequency distribution of the study variables is presented in the online Appendix S1. The column "All studies" in Table 1 presents the mean effect sizes, the 95\% confidence intervals, and the fail-safe numbers for the overall, aggregated outcome, and each outcome category. Community service yielded statistically significant, small to moderate effects in all outcome areas. Calculation of the fail-safe number revealed that 538 additional studies with nonsignificant results would have to exist in order to reduce the overall effect size below the conventional significance level of $p<$. 05. Between 2 (academic and career attitudes) and 76 (personal and social competence) of these kind of additional studies were needed to reduce the effect size per outcome category below this significance level.

To examine whether study outliers or methodological and publication characteristics could account for these effects, we examined their impact on the overall effect size. Similar effects were found when the only study with an extremely large effect size (Leming, 2001) was removed from the analysis, $k=48$, mean $\mathrm{ES}=.29,95 \%$ CI $[.21, .36], p<.01$, or 
Table 1

Mean Effect Sizes of Community Service on Adolescent Outcomes

\begin{tabular}{|c|c|c|c|c|c|c|c|c|}
\hline \multirow[b]{2}{*}{ Outcome } & \multicolumn{4}{|c|}{ All studies } & \multicolumn{4}{|c|}{ Studies including reflection } \\
\hline & $k$ & Mean ES & $95 \%$ CI & Fail-safe number & $k$ & Mean ES & $95 \%$ CI & Fail-safe number \\
\hline Overall & 49 & $.34^{* *}$ & $.22, .45$ & 539 & 34 & $.41^{* *}$ & $.27, .56$ & 128 \\
\hline Academic content and competence & 11 & $.45^{* *}$ & $.22, .68$ & 50 & 9 & $.55^{* *}$ & $.30, .81$ & 51 \\
\hline Academic and career attitudes & 14 & $.20^{\dagger}$ & $-.03, .42$ & 2 & 10 & $.36^{*}$ & $.08, .63$ & 14 \\
\hline Personal and social competence & 23 & $.25^{* *}$ & $.11, .39$ & 76 & 16 & $.34^{* *}$ & $.12, .55$ & 41 \\
\hline Attitudes toward the self & 15 & $.36^{*}$ & $.04, .69$ & 11 & 11 & $.41^{\dagger}$ & $-.03, .85$ & 3 \\
\hline Attitudes toward others & 22 & $.32^{* *}$ & $.12, .52$ & 59 & 15 & $.41^{* *}$ & $.13, .68$ & 32 \\
\hline Civic competence & 12 & $.35^{* *}$ & $.19, .50$ & 74 & 8 & $.40^{* *}$ & $.20, .60$ & 37 \\
\hline Civic attitudes & 22 & $.34^{*}$ & $.04, .64$ & 17 & 17 & $.40^{*}$ & $0, .79$ & 8 \\
\hline
\end{tabular}

Note. $k$ = number of studies included; Mean ES = mean effect size; $\mathrm{CI}=$ confidence interval; Fail-safe number = additional studies with nonsignificant or adverse results have to exist in order to reduce the effect size to below $p<.05$.

${ }^{\dagger} p<.10 .{ }^{*} p<.05 .{ }^{* *} p<.01$.

when three studies with an extremely large number of participants (Covitt, 2002; Komro et al., 2008; Luo et al., 2011) were removed from the analysis, $k=46$, mean $\mathrm{ES}=.35,95 \%$ CI $[.22, .49], p<.01$. Furthermore, no moderation was found when comparing: published to unpublished studies $\left(p_{\text {diff }}=.18\right)$, studies conducted in the United States to studies conducted in other countries $\left(p_{\text {diff }}=.42\right)$, studies that were published before 2001 to studies conducted during or after $2001\left(p_{\text {diff }}=.34\right)$, studies that did randomly assign community service to participants to studies that did not do this $\left(p_{\text {diff }}=.95\right)$, intervention to nonintervention studies $\left(p_{\text {diff }}=.75\right)$, studies in which the period between pretest and posttest was more than 1 year to studies in which this period was less than 1 year $\left(p_{\text {diff }}=.51\right)$, and studies that used self-reports to studies that used a combination of self-reports and other reports $\left(p_{\text {diff }}=.75\right)$.

\section{Moderation Effects of Reflection Characteristics: Comparing Community Service With and Without Reflection}

The column "Studies including reflection" in Table 1 presents the mean effect sizes, the $95 \%$ confidence intervals, and the fail-safe numbers for the overall, aggregated outcome and each outcome category for studies including reflection. As presented in Table 2, the overall community service effect was: mean ES $=.41,95 \%$ CI $[.27, .56], p<.01$. Calculation of the fail-safe number revealed that 128 additional studies with nonsignificant results have to exist in order to reduce this overall effect size below the conventional significance level of $p<$. 05. For studies in which participants did not use reflection, no overall (aggregated) effect of commu- nity service was found, mean $\mathrm{ES}=.05,95 \% \mathrm{CI}$ $[-.24, .35], p=.72$.

Table 2 also presents the moderation effects of the specific reflection characteristics we examined. For a number of reflection characteristics, we found significant, positive moderation effects when comparing studies that included these reflection characteristics with studies that did not include reflection at all. With regard to the quantity of reflection, we found a significant, positive relation between the frequency of reflection and the effect of community service. Furthermore, a stronger overall community service effect was found when studies included regular reflection (reflection before, during, and after community service) or included reflection only during or after community service. Furthermore, the form of reflection and the social context of reflection yielded significant moderation effects. We found positive effects for each form and each social context of reflection, except for reading on the topic of the community service activity (this moderator yielded a marginally significant, positive effect), using discussion as a reflection form, and for using a combination of writing, talking, and using artistic or nonverbal forms of reflection. Furthermore, the content of reflection yielded significant moderation effects. Positive effects were found for each content of reflection, except for reflection on self-related attitudes, social attitudes, and civic competence, and for the combination of self-related, social, and civic attitudes (this moderator yielded a marginally significant, positive effect). Furthermore, a stronger overall effect was found for studies in which there was a match between the reflection- and outcome category. Finally, no moderation effect was found for the overall quality of reflection. 
Table 2

Moderation by Reflection Characteristics: Comparisons Between Studies That Do and Do Not Include Reflection

\begin{tabular}{|c|c|c|c|c|c|c|c|}
\hline \multirow[b]{2}{*}{ Moderator } & \multicolumn{3}{|c|}{ Reflection } & \multicolumn{3}{|c|}{ No reflection } & \multirow[b]{2}{*}{$p_{\text {diff }}$} \\
\hline & $k$ & Mean ES & $95 \% \mathrm{CI}$ & $k$ & Mean ES & $95 \%$ CI & \\
\hline Reflection & 34 & $.41^{* *}$ & $.27, .56$ & 8 & .05 & $-.24, .35$ & $<.05$ \\
\hline \multicolumn{8}{|l|}{ Quantity of reflection } \\
\hline Frequency of reflection $^{\mathrm{a}}$ & 21 & & & & & & $<.01$ \\
\hline Regularity of reflection & 11 & $.26^{* *}$ & $.16, .36$ & 8 & .06 & $-.06, .18$ & $<.05$ \\
\hline Before community service & 12 & $.43^{* *}$ & $.14, .73$ & 8 & .05 & $-.31, .42$ & .11 \\
\hline During community service & 22 & $.45^{* *}$ & $.24, .65$ & 8 & .05 & $-.28, .39$ & .05 \\
\hline After community service & 19 & $.34^{* *}$ & $.22, .46$ & 8 & .06 & $-.13, .25$ & $<.05$ \\
\hline \multicolumn{8}{|l|}{ Form of reflection } \\
\hline Journal & 17 & $.24^{* *}$ & $.15, .34$ & 8 & .06 & $-.08, .20$ & $<.05$ \\
\hline Discussion & 22 & $.38^{* *}$ & $.19, .58$ & 8 & .05 & $-.27, .38$ & .09 \\
\hline Presentation & 9 & $.29 * *$ & $.16, .43$ & 8 & .06 & $-.09, .20$ & $<.05$ \\
\hline Reading & 8 & $.38^{* *}$ & $.14, .62$ & 8 & .06 & $-.18, .29$ & .06 \\
\hline Writing an essay & 8 & $.36^{* *}$ & $.23, .49$ & 8 & .06 & $-.07, .19$ & $<.01$ \\
\hline Creative way & 6 & $.30^{* *}$ & $.12, .47$ & 8 & .06 & $-.09, .21$ & $<.05$ \\
\hline Write, talk, and other way & 8 & $.21^{* *}$ & $.06, .36$ & 8 & .06 & $-.09, .21$ & .10 \\
\hline \multicolumn{8}{|l|}{ Context of reflection } \\
\hline Individually & 14 & $.24^{* *}$ & $.14, .35$ & 8 & .06 & $-.08, .20$ & $<.05$ \\
\hline Small peer group $(N=2-5)$ & 8 & $.36^{* *}$ & $.18, .54$ & 8 & .06 & $-.12, .24$ & $<.05$ \\
\hline Large peer group $(N=6-10)$ & 8 & $.33^{* *}$ & $.20, .47$ & 8 & .06 & $-.08, .19$ & $<.01$ \\
\hline Classroom & 19 & $.47^{* *}$ & $.24, .70$ & 8 & .05 & $-.29, .40$ & $<.05$ \\
\hline With teacher/supervisor & 17 & $.38^{* *}$ & $.24, .53$ & 8 & .06 & $-.16, .27$ & $<.05$ \\
\hline With others & 24 & $.47^{* *}$ & $.27, .66$ & 8 & .05 & $-.28, .38$ & $<.05$ \\
\hline \multicolumn{8}{|l|}{ Content of reflection } \\
\hline Academic content/competence & 6 & $.49^{* *}$ & $.39, .59$ & 8 & .06 & $-.02, .15$ & $<.01$ \\
\hline Academic and career attitudes & 8 & $.31^{* *}$ & $.15, .46$ & 8 & .06 & $-.09, .21$ & $<.05$ \\
\hline Self and social competence/behavior & 16 & $.32^{* *}$ & $.20, .45$ & 8 & .06 & $-.12, .24$ & $<.05$ \\
\hline Self-related attitudes & 15 & $.41^{* *}$ & $.16, .67$ & 8 & .05 & $-.30, .40$ & .11 \\
\hline Social attitudes & 15 & $.42^{* *}$ & $.17, .67$ & 8 & .05 & $-.29, .40$ & .10 \\
\hline Civic competence/behavior & 16 & $.37^{* *}$ & $.12, .62$ & 8 & .05 & $-.30, .41$ & .15 \\
\hline Civic attitudes & 12 & $.25^{* *}$ & $.13, .36$ & 8 & .06 & $-.08, .20$ & $<.05$ \\
\hline Self-, other-, and civic-related attitudes & 8 & $.25^{* *}$ & $.11, .39$ & 8 & .06 & $-.08, .20$ & .06 \\
\hline $\begin{array}{l}\text { Match between reflection and outcome content } \\
\text { category }\end{array}$ & 9 & $.59 * *$ & $.23, .95$ & 8 & .05 & $-.33, .43$ & $<.05$ \\
\hline Quality of reflection & 8 & $.23^{* *}$ & $.10, .36$ & 8 & .06 & $-.07, .19$ & .07 \\
\hline
\end{tabular}

Note. $k=$ number of studies included; Mean $\mathrm{ES}=$ mean effect size; $\mathrm{CI}=$ confidence interval; $p_{\text {diff }}=$ significance of moderation effect. ${ }^{\mathrm{a}}$ The frequency of reflection was used as a continuous variable: $B(S E)=.01(0), 95 \% \mathrm{CI}[.01, .02], \beta=.60, p<.01$.

$* * p<.01$.

\section{Moderation by Reflection Characteristics: Comparisons Among Reflection Characteristics}

For 17 of the 28 reflection characteristics enough studies for each level of the moderator were included to also compare one aspect of a reflection category with other aspects of the reflection category. This is equal to $61 \%$ of the studies. The effects of the following moderators could not be examined because cell sizes were too small: reflection during community service (quantity of reflection); discussion (form of reflection); individual reflection, classroom reflection, reflection with teacher/supervisor, reflec- tion with others (context of reflection); all of the content-related reflection aspects (content of reflection), except for reflection on academic content and academic attitudes, self-related, social-, and civic attitudes, and for the match between the content of the reflection and outcome category.

In contrast to the aforementioned moderation effects (in which one aspect of a reflection category was compared to no reflection), only a few moderation effects were found when comparing one aspect of a reflection category with other aspects of the reflection category. For the moderation effects that 
Table 3

Moderation by Community Service Characteristics and Person Characteristics

\begin{tabular}{|c|c|c|c|c|c|c|c|c|c|}
\hline Continuous moderators & $k$ & \multicolumn{2}{|c|}{$B(S E)$} & & $95 \% \mathrm{CI}$ & \multicolumn{3}{|c|}{$\beta$} & $p$ \\
\hline Quantity of community service (hours) & 26 & \multicolumn{2}{|c|}{$.00(0)$} & & $.0, .01$ & \multicolumn{3}{|c|}{.37} & .05 \\
\hline Age & 40 & \multicolumn{2}{|c|}{$.07(.03)$} & & $.01, .12$ & \multicolumn{3}{|c|}{.37} & $<.01$ \\
\hline Sex (percentage of boys) & 33 & \multicolumn{2}{|c|}{$-.09(.05)$} & & $-.20, .02$ & \multicolumn{3}{|c|}{-.27} & .11 \\
\hline & & & & \multicolumn{2}{|l|}{ Yes } & \multicolumn{3}{|c|}{ No } & \\
\hline \multicolumn{3}{|l|}{ Dichotomous moderators } & $k$ & Mean ES & $95 \% \mathrm{CI}$ & $k$ & Mean ES & $95 \% \mathrm{CI}$ & $p_{\text {diff }}$ \\
\hline \multirow{3}{*}{\multicolumn{3}{|c|}{$\begin{array}{l}\text { Kind of community service (vulnerable se } \\
\text { Required community service } \\
\text { Ethnic background (majority population) }\end{array}$}} & 23 & $.44^{* *}$ & $.23, .65$ & 7 & .23 & $-.14, .61$ & .34 \\
\hline & & & 17 & $.27^{*}$ & $.03, .50$ & 15 & $.55^{* *}$ & $.31, .80$ & .10 \\
\hline & & & 11 & $.46^{* *}$ & $.18, .75$ & 25 & $.36^{* *}$ & $.17, .55$ & .56 \\
\hline
\end{tabular}

Note. $k=$ number of studies included; $\mathrm{CI}=$ confidence interval; $p$ and $p_{\text {diff }}=$ significance of the moderation effect; Yes $=$ level of the dichotomous moderator present; $\mathrm{No}=$ level of the dichotomous moderator absent.

$* p<.05 . * * p<.01$.

could be examined we found a significant, positive effect for the frequency of reflection, $k=21$, $B(S E)=.01(0), 95 \%$ CI $[0, .02], \beta=.54, p<.01$, and a marginally significant, positive effect for reflection on academic content and competence-related topics: present, $k=6$, mean $\mathrm{ES}=.50,95 \%$ CI $[.28, .72]$, $p<.01 ;$ absent, $k=10$, mean $\mathrm{ES}=.24,95 \% \mathrm{CI}$ $[.07, .41], p<.01 ; p_{\text {diff }}=.06$.

\section{Moderation by (Other) Community Service Characteristics}

As presented in Table 3, a significant, positive correlation was found between the quantity of community service (community service hours) and the overall community service effect. Linearity represented the shape of the relation between the quantity of community service and community service effects most accurately, $F(1,24)=3.75, p=.07$. The larger the number of community service hours (range from 1 to $180 \mathrm{hr}$ of service), the larger was the impact of community service on adolescents. This moderation effect was also found when only studies including reflection were considered, $k=18$, $B(S E)=.05(0), 95 \%$ CI $[0, .01], \beta=.45, p<.05$.

The kind of community service did not moderate the overall community service effect. The overall community service effect was neither moderated by whether the community service was required or not.

\section{Moderation by Person Characteristics}

Table 3 reveals that adolescents' age, but not adolescents' sex or their ethnic background (whether adolescents came from a majority or from a minority or mixed population) moderated the service effect. Age was positively related to the overall community service effect: Studies with older adolescents found stronger community service effects. This moderation effect was also found when only studies including reflection were considered, $k=26$, $B(S E)=.08(.03), 95 \%$ CI $[.01, .14], \beta=.43, p<.05$.

Furthermore, for the moderation effects we have presented, we found almost no differences in the distribution of relevant continuous study characteristics (study participants' age, sex, number of community service hours, the frequency of reflection, and the kind of community service [the latter for moderation by whether community service was required]) between the different levels of the moderator variables. So the distribution of these characteristics cannot explain the found moderation effects. The only exceptions were that participants were older in studies that included reading on the topic of the community service as a reflection assignment or a creative way of reflection than in studies that used other forms of reflection. In addition, participants reflected more often in studies with participants that reflected by writing an essay than in studies with other forms of reflection.

\section{Correlations and Interactions Between Moderators}

The community service and adolescent characteristics that moderated community service effects (reflection or not; quantity of reflection, quantity of community service, and age) were uncorrelated (correlations ranged from $r \mathrm{~s}=-.21$ to .02 and were all nonsignificant), which indicates that these moderators had unique contributions to the overall community service effect. Furthermore, when these moderators were simultaneously regressed on the 
overall community service effect, we found the strongest effect for the quantity of reflection $(\beta s=.50-.70)$, the second strongest effect for age $(\beta s=.36-.50)$, and the least strong effect for the quantity of community service ( $\beta \mathrm{s}=.23-.35$ ).

We also found a positive, significant interaction between the quantity of reflection and the quantity of community service, $k=13, B(S E)=0(0), 95 \%$ CI $[0,0], \beta=.62, p<.01$. As visually presented in Figure S1 in the online Supporting Information, this means that the positive impact of the number of community service hours on the effect of community service increased when adolescents reflected more frequently. No other interactions between the examined moderators were found.

\section{Discussion}

We used meta-analysis to examine the impact of community service on adolescent developmental benefits and the moderating effects of qualities of reflection and service activities, and adolescent characteristics. Community service with reflection had robust, positive effects on adolescent developmental benefits. The overall effect of community service was only found when service included reflection. The overall effect was also stronger when reflection was performed more frequently, service was performed more often, and adolescents were older.

\section{Effects of Community Service and Moderation by Reflection}

Community service had small to moderate positive effects on all examined outcomes, as well as on the overall (aggregated) outcome. Our analysis indicates that adolescents benefit substantially from performing community service experiences; as a result of community service, adolescents develop their behaviors and attitudes in the academic, personal, social, and civic domains. Furthermore, our findings suggest that these effects cannot be explained by methodological artifacts or by study characteristics, such as time interval between measurements, outliers, or publication bias (the relatively high fail-safe numbers, especially for the overall effect size, suggest that these results are robust against the possibility of missing studies).

Our findings also indicate that the overall positive effect of community service requires reflection, as we found that there is no effect when adolescents do not reflect on their community service or service-related topics. Why does reflection have this effect? To better understand the influence of reflection, we examined the moderation effects of specific reflection characteristics including the quantity of reflection, the form of reflection, the social context of reflection, the content of reflection, and the overall quality of reflection. The majority of these reflection characteristics were positively associated with outcomes. For example, we found stronger community service effects for studies in which the content of reflection activities matched the content of the outcome category (e.g., "civic attitudes" was the outcome variable and adolescents reflected on their civic attitudes during service) compared to studies without reflection. This provides some indication for the specificity of reflection effects (e.g., Leming, 2001; cf. Waterman, 1997).

Important moderators of reflection included the frequency of reflection and reflection on academic content and competence, as they were also associated with beneficial outcomes when comparisons between reflection characteristics were made.

We found that the frequency of reflection (an element of the quantity of reflection) mattered; reflecting more often on community service experiences or related topics increased the overall impact of community service (e.g., Billig, 2009; Blyth et al., 1997; Scales et al., 2000). Reflecting more frequently could be important for effective community service as it can help adolescents interpret service experiences more thoroughly and internalize lessons learned (e.g., Eyler, 2002), which may optimize learning effects.

Reflecting on academic content and competence (an element of the content of reflection) was also found to stimulate the overall impact of community service on adolescent developmental benefits. It appears that theoretical knowledge and practical experience reinforce each other's impact in that way. By exploring different perspectives on community service, adolescents could process the content and meaning of their community service experiences more thoroughly and purposefully, causing stronger effects (e.g., Dymond, Renzaglia, \& Chun, 2007; Scales et al., 2000). In addition, it could be that reflection on academic content (topics taught in school courses) often involves thinking about topics that have a strong and specific connection to the community service that is performed. For example, in a study by Moss (2009) adolescents reflected on various aspects (e.g., historical and political aspects) of the Vietnam War and on World War II in a history course, before they made an oral history archive out of personal interviews with war 
veterans. This archive was used to preserve oral history of civic issues and was available as material for courses on (civic) history in a nearby university. In this example there was a direct link between the content of the reflection and the community service performed, which may have stimulated adolescents' understanding and generalization of both the service experience (e.g., understanding these personal war stories in their historical and political context), as well as the concepts connected to these experiences (e.g., being better able to remember and understand the various aspects of these wars; Eyler, 2002; Hatcher et al., 2004; Ogden \& Claus, 2006).

\section{Moderation by (Other) Community Service Characteristics}

The quantity of community service moderated the overall service effect: Adolescents profited more from community service when it was performed more frequently (e.g., Billig, 2009; Hecht, 2003; Melchior \& Bailis, 2002). We did not find any indication for a cutoff point at which the benefits of community service may level off or become counterproductive (e.g., Conway et al., 2009). The positive effect of community service even seemed to last up until $180 \mathrm{hr}$ of service, which is equal to 4.5 weeks of service.

Whether the community service was required did not moderate the overall service effect. This means that adolescents generally learn and profit from their community service, independent of whether its initiation is required by others. In contrast to what is suggested by some researchers, required and unrequired community service did not differ on the quantity of community service or on the kind of community service.

The kind of community service, that is, whether the community service did or did not involve personal contact with vulnerable service groups in need of that service, did not moderate the overall community service effect. Based on the literature, three explanations for this finding are plausible. First, it could be that although some (types of) adolescents may benefit and learn from these kinds of community service, others may not, for example, because they are overwhelmed or discouraged by these experiences (cf. Kahne \& Westheimer, 2006; Karafantis \& Levy, 2004). Second, it could be that service for vulnerable groups in need has no overall positive effect, but only has positive effects for specific outcomes or outcome domains such as their moral development, civic responsibility, and civic engagement (cf. McLellan \& Youniss, 2003;
Reinders \& Youniss, 2006). Third, it could be that influential kinds of community service with vulnerable groups require even more detailed characteristics than we studied. For example, adolescents feel they make a positive contribution with their service activity (cf. Furco, 2002; Root \& Billig, 2008). It could therefore be valuable for future studies to further explore the (proposed) processes and factors that may explain this finding.

\section{Moderation by Person Characteristics}

We found a positive moderation effect of age, which suggests that community service has a stronger effect when adolescents are older. This has also been found in some earlier studies on community service effects (e.g., Hecht, 2003; Melchior \& Bailis, 2002) and is consistent with current knowledge on cognitive, moral, and identity development. When adolescents become older they are better able to process and integrate new experiences (e.g., identity integration; van Hoof \& Raaijmakers, 2002), consider and value the perspectives and needs of others (e.g., Eisenberg et al., 2005), and further develop their civic identities (e.g., Youniss et al., 1997): all factors that could make adolescents more open to community service experiences. Adolescents' sex and their ethnic background did not moderate the overall community service effect. This indicates that, generally, community service is as effective for boys as it is for girls and as effective for adolescents from ethnic majority populations as it is for adolescents from ethnic minority or mixed populations.

We found that more frequent community service and more frequent reflection reinforced each other's impact on the overall community service effect. This suggests that adolescents learn even more from intensive service experiences when accompanied by more frequent reflection, as it may allow them to process the content and meaning of these experiences more thoroughly (cf. Blyth et al., 1997).

\section{Strengths, Limitations, and Future Research}

This study has three major strengths: First, this meta-analysis only includes studies that contained a treatment and control group with pre- and postassessments, which enables making causal inferences on community service effects. Second, this study was the first meta-analysis that thoroughly examined whether and how specific characteristics of reflection affected community service effects. This was enabled by the acquisition of additional information on these reflection characteristics from study 
authors. Third, it is one of the few studies that examined whether other, theoretically relevant community service characteristics and person characteristics affected community service effects and whether these characteristics interacted with reflection. Together these findings contribute to a better understanding of the conditions and processes by which community service affects adolescent developmental benefits.

Although we were able to examine relatively specific community service effects and moderator effects, the meta-analytic approach entails certain limitations. First, the number of studies with specific combinations of characteristics is limited, as is the information on the specifics of services and participants. For example, we were not able to assess in more detail which adolescents profit most from which kind of community service (e.g., serving a vulnerable service group). Neither were we able to assess whether randomization of the community service may have affected specific outcomes. Therefore, moderator analyses were limited to those aspects of the moderator for which sufficient information was provided in a sufficient number of studies (Lipsey \& Wilson, 2001). This also prevented us from examining moderation effects for specific outcome domains, including the examination of whether community service for vulnerable service groups may only have positive effects for specific outcomes such as social and civic outcomes (McLellan \& Youniss, 2003; Reinders \& Youniss, 2006). Also, more generally, for some moderators the extent of missing data was considerable, which lowered the statistical power to test for moderation effects and the generalizability of these effects.

Second, even though we can make causal inferences on the main effect of community service, it does not allow making causal inferences on the moderation effects of (specific) community service or reflection characteristics because these characteristics were not experimentally manipulated. To gain more detailed insight into effective ingredients of community service, research could benefit from more experimental designs to manipulate specific elements of community service. This is also important as we found that most of the included studies used numerous kinds of reflection simultaneously. This makes assessing differences between effects of specific kinds of reflection hard, or sometimes even impossible (for 39\% of the assessed reflection characteristics fewer than four studies did not include the assessed reflection characteristic, which prevented calculating its moderation effect).
In addition to using more experimental designs, more long-term longitudinal research could further improve knowledge on the stability or growth of community service effects (e.g., Celio et al., 2011; Hart et al., 2008). In this meta-analysis, only four studies examined the effect of community service on adolescents' developmental benefits over a period of more than 1 year. By implementing more long-term studies, a better understanding can be obtained of how community service affects adolescents over time and whether community service and reflection has a lasting effect.

Furthermore, the validity of community service research could be improved by including more objective measures of service effects (e.g., Celio et al., 2011). In our meta-analysis, $80 \%$ of the studies solely used self-report measures. Although self-reports are valid ways to assess thoughts and experiences among adolescents (e.g., Hart \& Carlo, 2005), they can also be influenced by social desirability (e.g., Moely, Mercer, Illustre, Miron, \& McFarland, 2002). This can especially be a problem in community service research, as doing service is generally perceived as positive (cf. Hart, Matsuba, \& Atkins, 2014): Service is an important societal value, which may give rise to personal and social expectations of performing community service. Adding more objective measures, especially for the behavioral and competence-related outcomes of community service, would be a valuable addition to present studies on service effects. These more objective measures could include: competence and behavioral measures (e.g., school grades or counts of signing up for community service activities), observations, and relatively independent reports on adolescents' behaviors (preferably by persons who are not involved in, or aware of adolescents' community service; e.g., Celio et al., 2011).

Third, we were not able to control or consider all relevant contextual effects that may have influenced our findings. These contexts involve the influence of the environment on a microlevel such as the community service expectations or values of significant adults (parents, teachers, supervisors). For example, community service programs can have goals that are more focused on stimulating adolescents' altruism and moral responsibility or on stimulating learning and critically thinking about civic issues and civic activism (see also Hart et al., 2008). In addition, these influential contexts also involve the macro level such as the country in which the study was conducted (e.g., Torney-Purta \& Amadeo, 2003). Most research on community service is conducted in the United States and therefore the large majority of 
the studies included in this meta-analysis were also performed in the United States $(87 \%)$. To examine the generalizability of our findings to other countries, and thus cultural and societal contexts, more replication studies in other Western and non-Western countries are needed.

\section{General Conclusion and Implications}

This meta-analysis shows that community service including reflection has positive effects on the way adolescents behave and think about school, themselves, others, and society. These findings are promising for educators and practitioners who implement community service in adolescent populations as they indicate that community service could be a valuable intervention to promote adolescent development. Furthermore, our findings contribute to a better understanding of what constitutes effective community service which can be used to improve the efficacy of community service programs. Our findings suggest that intensive community service programs in which adolescents have to perform frequent community service and reflection are generally beneficial. Community service may also be more effective when adolescents reflect on academic topics, taught in courses that are part of the school curriculum (e.g., sociology). By applying these topics to their service experiences, adolescents may learn more about these topics. Moreover, by connecting and integrating community service into an academic course, adolescents may be better able to understand the meaning of their service experiences. In addition, it can be valuable to implement community service at the end of high school (e.g., in their pregraduation year), as the older adolescents are, the more beneficial community service generally is.

\section{References}

Atkins, R., Hart, D., \& Donnelly, T. M. (2005). The association of childhood personality type with volunteering during adolescence. Merrill-Palmer Quarterly, 51, 145162.

Batchelder, T. H., \& Root, S. (1994). Effects of an undergraduate program to integrate academic learning and service: cognitive, prosocial cognitive, and identity outcomes. Journal of Adolescence, 17, 341-355.

Bekkers, R. (2007). Intergenerational transmission of volunteering. Acta Sociologica, 50, 99-114. doi:10.1177/ 0001699307077653

Billig, S. H. (2009). Does quality really matter? In B. E. Moely, S. H. Billig, \& B. A. Holland (Eds.), Creating our identities in service-learning and community engagement (pp. 131-157). Greenwich, CT: Information Age.

Billig, S. H., \& Northup, J. (2008). K-12 Service-learning standards for quality practice. An annotated bibliography. St. Paul, MN: National Leadership Council. Retrieved from http://www.nylc.org/k-12-service-learning-standards-and-indicators-quality-practice.

Billig, S. H., \& Weah, W. (2008). K-12 service-learning standards for quality practice. In J. C. Kielsmeier, M. Neal, N. Schultz, \& T. J. Leeper (Eds.), Growing to greatness 2008: The state of service-learning project (pp. 8-15). St. Paul, MN: National Youth Leadership Council.

Blyth, D., Saito, R., \& Berkas, T. (1997). A quantitative study of the impact of service-learning programs. In A. Waterman (Ed.), Service-learning: Applications from the research (pp. 39-55). Mahwah, NJ: Erlbaum.

Bringle, R. G., \& Hatcher, J. A. (1999). Reflection in service learning: Making meaning of experience. Educational Horizons, Summer, 77, 179-185.

Catalano, R. F., Haggerty, K. P., Oesterle, S., Fleming, C. B., \& Hawkinds, J. D. (2004). The importance of bonding to school for healthy development: Findings from the Social Development Research Group. Journal of School Health, 74, 252-261.

Celio, C. I., Durlak, J., \& Dymnicki, A. (2011). A metaanalysis of the impact of service-learning on students. Journal of Experiential Education, 34, 164-181. doi:10. 5193/JEE34.2.164

Conway, J. M., Amel, E. L., \& Gerwien, D. P. (2009). Teaching and learning in the social context: A metaanalysis of service-learning's effects on academic, personal, social, and citizenship outcomes. Teaching of Psychology, 36, 233-245. doi:10.1080/00986280903172969

Covitt, B. A. (2002). Motivating environmentally responsible behavior through service-learning. In S. H. Billig \& A. Furco (Eds.), Service-learning through a multidisciplinary lens (pp. 177-197). Greenwich, CT: Information Age.

Dymond, S. K., Renzaglia, A., \& Chun, E. (2007). Elements of effective high school service learning programs that include students with and without disabilities. Remedial and Special Education, 28, 227-243.

Eisenberg, N., Cumberland, A., Guthrie, I. K., Murphy, B. C., \& Shepard, S. A. (2005). Age changes in prosocial responding and moral reasoning in adolescence and early adulthood. Journal of Research on Adolescence, 15, 235-260. doi:10.1111/j.1532-7795.2005.00095.x

Eyler, J. (2001). Creating your reflection map. In M. Canada (Ed.), Service learning: Practical advice and models. San Francisco, CA: Jossey-Bass.

Eyler, J. (2002). Reflection: Linking service and learning. Linking students and communities. Journal of Social Issues, 58, 517-534. doi:10.1111/1540-4560.00274

Eyler, J. S., Giles, D. W., Stenson, C. M., \& Gray, C. J. (2001). At a glance: What we know about the effects of service-learning on college students, faculty, institutions and communities, 1993-2000 (3rd ed.) Washington, DC: 
Learn \& Serve America/National Service-Learning Clearinghouse.

Furco, A. (2002). Is service-learning really better than community service? In A. Furco \& S. H. Billig (Eds.), Service-learning. The essence of pedagogy (pp. 42-50). Greenwich, CT: Information Age.

Haidt, J. (2001). The emotional dog and its rational tail. Psychological Review, 108, 814-834. doi:10.1037// 0033-295X.108.4.814

Hamilton, S. F., \& Fenzel, L. M. (1988). The impact of volunteer experience on adolescent social development: Evidence of program effects. Journal of Adolescent Research, 3, 65-80.

Hart, D., Atkins, R., Markey, P., \& Youniss, J. (2004). Youth bulges in communities: The effects of age structure on adolescent civic knowledge and civic participation. Psychological Science, 15, 591-597.

Hart, D., \& Carlo, G. (2005). Moral development in adolescence. Journal of Research on Adolescence, 15, 223-233. doi:10.1111/j.1532-7795.2005.00094.x

Hart, D., Donnelly, T. M., Youniss, J., \& Atkins, R. (2007). High school community service as a predictor of adult voting and volunteering. American Educational Research, 44, 197-219. doi:10.3102/0002831206298173

Hart, D., Matsuba, M. K., \& Atkins, R. (2008). The moral and civic effects of learning to learning. In L. P. Nucci \& D. Narvaez (Eds.), Handbook of moral and character education (pp. 484-499). New York: Routledge.

Hart, D., Matsuba, M. K., \& Atkins, R. (2014). Civic engagement and child and adolescent well-being. In A. Ben-Arieh, F. Casas, I. Frones, \& J. E. Korbin (Eds.), Handbook of child well-being: Vol. 2. Theories, methods and policies in a global perspective (pp. 957-976). Dordrecht, Netherlands: Springer.

Hatcher, J. A., \& Bringle, R. G. (1997). Reflection: Bridging the gap between service and learning. Journal of College Teaching, 45, 153-158. doi:10.1080/ 87567559709596221

Hatcher, J. A., Bringle, R. G., \& Muthiah, R. (2004). Designing effective reflection: What matters to service learning? Michigan Journal of Community Service Learning, 11, 38-46.

Hecht, D. (2003). The missing link. Exploring the context of learning in service-learning. In S. H. Billig \& J. Eyler (Eds.), Deconstructing service-learning. Research exploring context, participation, and impacts (pp. 25-49). Greenwich, CT: Information Age.

Hedges, L. V., \& Olkin, I. (1985). Statistical methods for meta-analysis. Boston, MA: Academic Press.

Higgins, J. P. T., \& Green, S. (Eds.). (2006). Cochrane handbook for systematic reviews of interventions, version 4.2 .6 (updated September 2006). The Cochrane Collaboration. Retrieved from http://www.cochrane-handbook. org

Juni, P., Witschi, A., Bloch, R., \& Egger, M. (1999). The hazards of scoring the quality of clinical trials for metaanalysis. Journal of the American Medical Association, 282, 1054-1060.
Kahne, J., \& \& Westheimer, J. (2006). The limits of political efficacy: Educating citizens for a democratic society. PS: Political Science and Politics, 39, 289-296. doi: http://www.jstor.org/action/showPublication?journalCode $=$ pspolisciepoli

Karafantis, D. M., \& Levy, S. R. (2004). The role of children's lay theories about the malleability of human attributes in beliefs about and community service for disadvantaged groups. Child Development, 75, 236-250. doi:10.1111/j.1467-8624.2004.00666.x

Komro, K. A., Perry, C. L., Veblen-Mortenson, S, Farbakhsh, K, Toomsey, T. L., Stigler, M. H., \& . . . Williams, C. L. (2008). Outcomes from a randomized controlled trial of a multi-component alcohol use preventive intervention for urban youth: Project Northland Chicago. Addiction, 103, 606-618.

Leming, J. S. (2001). Integration a structured ethical reflection curriculum into high school community service experiences: Impact on students' social-moral development. Adolescence, 36, 33-45.

Lipsey, M. W., \& Wilson, D. B. (2001). Practical metaanalysis. Thousand Oaks, CA: Sage.

Luo, R., Shi, Y., Zhang, L., Liu, C., Li, H., Rozelle, S., \& Sharbono, B. (2011). Community service, educational performance and social responsibility in Northwest China. Journal of Moral Education, 40, 181-202.

Maryland State Department of Education. (n.d.) Graduation requirements. Retrieved from http:/ / www.marylandpublicschools.org/MSDE/programs/servicelearning/docs/ requirements.htm/

McLellan, J. A., \& Youniss, J. (2003). Two systems of youth service: Determinants of voluntary and required youth community service. Journal of Youth and Adolescence, 32, 47-58.

Melchior, A., \& Bailis, L. N. (2002). Impact of servicelearning on civic attitudes and behaviors of middle and high school youth. Findings from three national evaluations. In A. Furco \& S. H. Billig (Eds.), Service-learning. The essence of pedagogy (pp. 201-221). Greenwich, CT: Information Age.

Metzger, A., \& Smetana, J. G. (2009). Adolescent civic and political engagement: Associations between domain-specific judgments and behavior. Child Development, 80, 433-441.

Moely, B. E., Mercer, S., Illustre, V., Miron, D., \& McFarland, M. (2002). Psychometric properties and correlates of the Civic Attitudes and Skills Questionnaire (CASQ): A measure of students' attitudes related to service-learning. Michigan Journal of Community Service Learning, 8, 15-26.

Molee, L. M., Henry, M. E., Sessa, V. I., \& McKinneyPrupis, E. R. (2010). Assessing learning in service-learning courses through critical reflection. Journal of Experiential Education, 33, 239-257. doi:10.5193/JEE33.3.239

Moss, L. J. (2009). Effects of service-learning on student attitudes toward academic engagement and civic responsibility (Unpublished dissertation). Florida International University, Miami. 
National Centre for Social Research and the Institute for Volunteering Research. (2007). Helping out: A national survey of volunteering and charitable giving. Prepared for the UK Cabinet Office.

Novak, J. M., Markey, V., \& Allen, M. (2007). Evaluating cognitive outcomes of service learning in higher education: A meta-analysis. Communication Research Reports, 24, 149-157. doi:10.1080/08824090701304881

Ogden, C., \& Claus, J. (2006). Reflection as a natural element of service: Service learning for youth empowerment. Equity and Excellence in Education, 30, 72-80. doi:10.1080/1066568970300110

Ostheim, P. Q. (1995). Effects of community service and service learning on multidimensional self concept of secondary school students (Unpublished doctoral dissertation). North Carolina State University, Raleigh.

Pizarro, D. A., \& Bloom, P. (2003). The intelligence of moral intuitions: Comment on Haidt (2001). Psychological Review, 110, 193-196. doi:10.1037/0033-295X.110.1. 193

Raudenbush, S. W. (2009). Analyzing effect sizes: Random effects models. In H. Cooper, L. V. Hedges, \& J. C. Valentine (Eds.), The handbook of research synthesis and meta-analysis (2nd ed., pp. 295-315). New York, NY: Russell Sage Foundation.

Reinders, H., \& Youniss, J. (2006). School-based required community service and civic development in adolescents. Applied Developmental Science, 10, 2-12. doi: 10.1207/s1532480xads1001_1

Rijksoverheid. (2007). Coalitieakkoord tussen de Tweede Kamerfracties van CDA, PvdA en ChristenUnie. Retrieved from http://www.rijksbegroting.nl/rijksbegrotingsarchief/regeerakkoorden/regeerakkoord_2007.pdf/

Root, S., \& Billig, S. H. (2008). Service-learning as a promising approach to high school civic engagement. In J. Bixby \& J. Pace (Eds.), Educating democratic citizens in troubled times: Qualitative studies of current efforts. Albany, NY: SUNY Press.

Scales, P. C., Blyth, D. A., Berkas, T. H., \& Kielsmeier, J. C. (2000). The effects of service-learning on middle school students' social responsibility and academic success. Journal of Early Adolescence, 20, 332-358. doi: $10.1177 / 0272431600020003004$

Steinke, P., Fitch, P., Johnson, C., \& Waldstein, F. (2002). An interdisciplinary study of service learning outcomes. In A. Furco \& S. H. Billing (Eds.), Advances in service learning research, (Vol. 2, pp. 103-122). Greenwich, CT: Information Age.

Stukas, A. A., Clary, E. G., \& Snyder, M. (1999). Service learning: Who benefits and why. Social Policy Report: Society for Research in Child Development, 13, 1-19.

Sundeen, R. A., Garcia, C., \& Raskoff, S. A. (2009). Ethnicity, acculturation, and volunteering to organizations: A comparison of African Americans, Asians, Hispanics, and Whites. Nonprofit and Voluntary Sector Quarterly, 38, 929-955. doi:10.1177/0899764008322779

Switzer, G. E., Simmons, R. G., Dew, M. A., Regalski, J. M., \& Wang, C. (1995). The effect of school-based helper program on adolescent self-image, attitudes, and behavior. Journal of Early Adolescence, 15, 429-455.

Toole, J., \& Toole, P. (1995). Reflection as a tool for turning service experiences into learning experiences. In C. Kinsley \& K. McPherson (Eds.), Enriching the curriculum through service-learning (pp. 99-114). Alexandria, VA: Association for Supervision Curriculum and Development.

Torney-Purta, J., \& Amadeo, J. A. (2003). A cross-national analysis of political and civic involvement among adolescents. PS: Political Science and Politics, 26, 269-274.

van Goethem, A. A. J., van Hoof, A., van Aken, M. A. G., Raaijmakers, Q. A. W., Boom, J., \& Orobio de Castro, B. (2012). The role of adolescents' morality and identity in volunteering. Age and gender differences in a process model. Journal of Adolescence, 35, 509-520. doi: 10.1016/j.adolescence.2011.08.012

van Hoof, A., \& Raaijmakers, Q. A. W. (2002). The spatial integration of adolescent identity: Its relation to age, education, and subjective well-being. Scandinavian Journal of Psychology, 43, 201-212.

Warter, E. H., \& Grossman, J. M. (2002). An application of contextualism to service-learning. In A. Furco \& S. H. Billig (Eds.), Service-learning. The essence of pedagogy (pp. 83-102). Greenwich, CT: Information Age.

Waterman, A. S. (1997). An overview of service-learning and the role of research and evaluation in service-learning programs. In A. Waterman (Ed.), Service-learning: Applications from the research (pp. 39-55). Mahwah, NJ: Erlbaum.

White, A. (2001). Meta-analysis of service-learning research in middle and high schools (Unpublished doctoral dissertation). University of North Texas, Denton.

Wilson, J. (2000). Volunteering. Annual Review of Sociology, 26, 215-240.

Youniss, J., McLellan, J. A., \& Yates, M. (1997). What we know about engendering civic identity. American Behavioral Scientist, 40, 620-631. doi:10.1177/000276429 7040005008

Youniss, J., \& Yates, M. (1997). Community service and social responsibility. Chicago, IL: University of Chicago Press.

\section{Supporting Information}

Additional supporting information may be found in the online version of this article at the publisher's website:

Figure S1. Interaction Between the Quantity of Community Service and the Quantity of Reflection in Relation to the Overall Effect Size

Appendix S1. Coding Scheme for the Studied Variables $(k=49)$

Appendix S2. Studies Included in the MetaAnalysis 